\title{
Serial, parallel, or holistic identification of single words in the two visual fields?
}

\author{
JOHN L. BRADSHAW, DIANNE BRADLEY, ANNE GATES, and KAY PATTERSON \\ Monash University, Clayton, Victoria 3168, Australia
}

\begin{abstract}
Subjects made timed manual responses in judging whether laterally presented four-letter words were identical to targets. In Experiment 1, nontargets differed by a single letter from targets. A right-field superiority occurred only for targets (which were detected fastest of all) and for nontargets where a letter changed at Position 2 or Position 3. Changes at initial and final positions were detected faster than the two middle positions, and there were no significant field differences. In Experiment 2, ascenders and descenders were controlled and changes were made in nontargets at all four letter positions, at Positions 1 and 4, at Positions 2 and 3 , or at 2 alone. Response times for nontargets varied inversely with the number of differing letters, regardless of position. Significant field differences again only appeared for changes in the two middle positions. Letters at the beginning and end of a word seem to be processed faster than and differently from those within, where field differences are strongest. Vowel-consonant differences probably do not account for these effects, which are more compatible with some form of parallel, rather than either serial or holistic, processing.
\end{abstract}

A right-field superiority is typically found when single letters or numbers are presented for detection and either recognition accuracy (Carmon, Kleiner, \& Nachshon, 1975; Cohen, 1976; Hines \& Satz, 1971) or response times are measured (Bradshaw, Bradley, \& Patterson, 1976; Cohen, 1974; Geffen, Bradshaw, \& Wallace, 1971; McKeever, Gill, \& Van Deventer, 1975; Moscovitch, 1973; Rizzolatti, Umiltà, \& Berlucchi, 1971). A left-field (right-hemisphere) superiority may be induced in the presence of an additional verbal task (Geffen, Bradshaw, \& Nettleton, 1973), or when large physical aspects of these verbal stimuli are important (Bryden \& Allard, 1976; Cohen, 1972; Davis \& Schmit, 1973; Geffen, Bradshaw, \& Nettleton, 1972; Umiltà, Frost, \& Hyman, 1972). With words, right-field superiorities have been attributed partly to left-right directional scanning (see Bradshaw, 1975; White, 1969, 1973, for reviews). However, several studies suggest that cerebral dominance is a more fundamental mechanism (Barton, Goodglass, \& Shai, 1965; Carmon, Nachson, Isser off, \& Kleiner, 1972; Isseroff, Carmon, \& Nachshon, 1974; Marcel, Katz, \& Smith, 1974).

To date, comparatively few studies have presented whole words to left or right visual fields, partly perhaps because of uncertainty as to the possible contribution of scanning effects. Joynt and Goldstein (1975) review the ability of commissurotomy patients

This work was supported by a grant to the first author by the Australian Research Grants Committee. Please address requests for reprints to: John L. Bradshaw, Department of Psychology, Monash University, Clayton, Victoria 3168, Australia. D. Bradley is now at the Massachusetts Institute of Technology. to recognize by gesture simple concrete nouns flashed to the right hemisphere. With normal subjects, differential field effects have been reported for concreteness, familiarity, imageability, and frequency (Ellis \& Shepard, 1974; Hines, 1976; Marcel \& Patterson, in press; though see Caplan, Holmes, \& Marshall, 1974, for negative results).

One aim of the two experiments we report was to cast more light on the possible involvement of serial left-to-right scanning in inducing field differences with laterally presented words. More particularly, we hoped to determine whether there were field differences in the discrimination of orthographically very similar target and nontarget words, and to examine the effect of letter changes, in nontargets, at the beginning, middle, and end positions. Subjects were presented with lowercase four-letter words, in left or right visual field, for matching to a stored target word. Test items either were identical to the target or systematically differed by one or more letter positions. In the second experiment, word shape in terms of ascenders and descenders was also controlled. Words, rather than nonword letter strings were employed because the unfamiliarity of the latter would have unacceptably increased the level of task difficulty, and perhaps also the likelihood of subjects deliberately adopting strategies of serial scanning, or phonological coding and comparison, or both.

\section{EXPERIMENT 1}

This experiment aimed to determine the nature and extent of field differences, as measured by manual discriminatory reaction time, when a subject matched a tachistoscopically presented test word 
(four-letter, lowercase, in right or left visual field) to a stored target item. The test item either was identical to the target or differed from it by one letter, with the change occurring with equal probability at any of the four letter positions.

\section{Method}

Subjects. The 16 subjects, 8 male and 8 female, were graduate students and staff at Monash University. All were right-handed, without left-handed close relatives, and had normal or correctedto-normal vision. Vision and handedness were tested by a procedure described by Patterson and Bradshaw (1975).

Materials. Seventeen families (16 experimental, 1 practice) of four-letter words, five words in each family, were generated according to the following constraints. All words were singlesyllable, and each letter of the target word could be changed so as to produce a new word, e.g., chip (target), ship, clip, chap, chin. The constraints of producing familiar real words which each differed by a single letter from a target word meant that exact equivalence of frequencies was unattainable. However, according to the Kutera-Francis (1967) frequency counts, median frequencies for target and nontargets, according to position of change 1 to 4 , were: $23,36,18,21,22$ (per million).

Each word was typed in lower case with a carbon ribbon on white card. Photographic negatives $(35 \mathrm{~mm})$ of each word were produced, one for the left visual field and one for the right. When mounted in slide holders, these were projected onto a backprojection screen, either to the left or right of fixation, by a projection tachistoscope (Vincent, Bradshaw, Nettleton \& Donahoo, 1973). The dimensions, viewed from a distance of $68 \mathrm{~cm}$, were such as to replicate the visual angles projected by normal typescript at a standard reading distance of about $30 \mathrm{~cm}$. Each four-letter word subtended an angular width of $2.5 \mathrm{deg}$; the distance from fixation point to the nearest edge of each word was $1.0 \mathrm{deg}$ and to the furthest was $3.5 \mathrm{deg}$.

Procedure. The subject sat with his head in a chinrest, facing the back-projection screen. A block of stimuli consisted of 16 trials, with eight presentations in each visual field. Of these, four were the target word and four were one presentation, again in each visual field, of each of the other four nontarget words. Over the 16 trials of each block, target and nontarget items and leftand right-field presentations were pseudorandomly varied, with the order differing for each block. Before each block of 16 trials, the experimenter repeated the target word to the subject, who wrote it five times in lower case to familiarize himself with it for that block of trials. Each trial was preceded by a warning tone (1 $\mathrm{kHz}$ ) of $1 \mathrm{sec}$, at the onset of which a fixation point, a red light-emitting diode, began to flash in the middle of the screen. The test item was then presented for $150 \mathrm{msec}$.

The subject responded by pressing buttons on a panel in front of him, stopping an electronic millisecond timer which had started at stimulus onset. The response panel consisted of four buttons where, for half the subjects, the forefingers of the two hands pressed the nearer buttons ("target" keys) and the middle fingers pressed the other two buttons further away ("nontarget"' keys). This procedure was reversed for the rest of the subjects. Although the subjects were told it was necessary to press the buttons simultaneously, the first button depressed stopped the timer. The use of this bimanual response was designed to avoid the problem of one hand or hemisphere leading (Geffen et al., 1972). Each subject was instructed to respond as quickly and as accurately as possible, the best strategy being to fixate the flashing red light at the commencement of the warning tone.

Any errors or long reaction times (which exceeded by an arbitrarily set criterion of $500 \mathrm{msec}$ the subject's average during the practice block) were replaced at the end of the block in which they occurred. The repeats were made with maintenarice of the ordering and sequencing constraints described above, and without the subject's knowledge that they were repeats. An experimental session lasted for about $1 \mathrm{~h}$.

\section{Results}

The data (see Figure 1) were subjected to analysis of variance by Sex, Target/Nontarget, and Visual Field, with repeated measures on the last two factors. Females $(587 \mathrm{msec}$ ) were nonsignificantly faster than males (636 msec). Target stimuli (591 msec) were detected significantly faster than nontargets $(632 \mathrm{msec})$, $\mathrm{F}(1,14)=58.9 ; \mathrm{p}<.001$. The right visual field $(603 \mathrm{msec})$ proved to be significantly faster than the left $(621 \mathrm{msec}), F(1,14)=20.1, p<.001$. None of the interactions reached significance.

The data for the four change positions in the nontarget items can be examined separately. When this is done, Sex continues to be nonsignificant, the right visual field $(625 \mathrm{msec})$ continues to be faster than the left $(639 \mathrm{msec}), F(1,14)=8.04, \mathrm{p}<.025$, and the main effect Change is also significant, $F(1,14)=$ $58.1, \mathrm{p}<.001$. The only significant interaction is Change by Visual Field, $F(1,14)=6.37, p<.025$. This shows that the strength of the right-field superiority varies across the different change positions. Using $t$ tests for correlated samples, a significant right-field superiority is found only for the middle positions, 2 and 3 , respectively, $t(15)=3.4$,

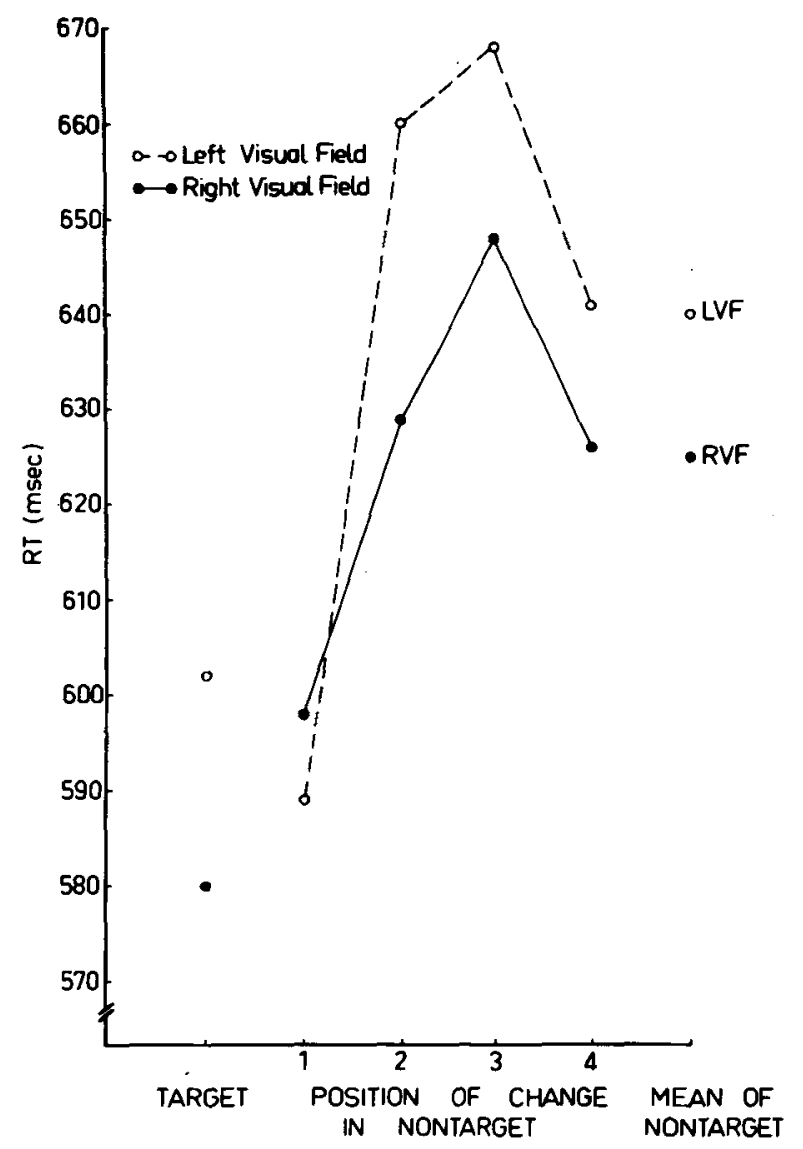

Figure 1. Reaction times averaged across 16 subjects in Experiment 1 for target words and for nontargets differing from targets by one letter at each of the four positions of change. Left and right visual fields shown separately. 
$\mathrm{p}<.01$, and $\mathrm{t}(15)=2.6, \mathrm{p}<.02$. It is noteworthy that neither the small left-field superiority for the initial change position nor the small right-field superiority for the final change position (where, in both cases, these letters were maximally distant from the fovea) reaches significance. As can be seen from Figure 1, the significant right-field superiorities for nontargets with changes at the two middle positions is similar in magnitude to that of the target items. Using the Newman-Keuls procedure (Winer, 1971) and collapsing across visual fields, it is possible to ascertain that a change at the first position is detected faster than one at all of the other three positions, in each case at $p<.01$. A change at the final position is also detected significantly faster $(p<.05)$, than one at the penultimate position (3). There is no significant difference between either of the other two remaining pairs (i.e., between changes at the two middle positions 2 and 3 , or between changes at Positions 2 and 4 ). This suggests not only that field differences are only found for changes in the middle positions of the word, but also that changes at the beginnings and ends (particularly the beginnings) are detected faster than and differently from those in the middle. Indeed, the absence of a significant difference between the two middle positions, and the relative superiority of the end position, argues against the operation of a serial left-to-right scan in this task.

A problem arising from the constraints imposed by the orthography and structure of English fourletter words is the fact that vowels and consonants are not evenly distributed across all letter positions. Thus, taking the 80 experimental words used here (16 targets and 16 sets of nontargets with a change at each of the four-letter positions) and counting the number of vowels at each of the letter positions from 1 to 4 , values are obtained of $0,65,20,25$-the 25 vowels in the last position always being unsounded $e$. Thus, vowels are nonexistent at the first position, and also at the last (except for e), and most common at the second. Single-syllable four-letter words will, of course, inevitably tend to have more vowels in the middle; in fact the only two other possible formats, vowel-vowel-consonant-consonant (e.g., "east") and consonant-consonant-vowel-vowel (e.g., "flee"), do not generate many words. The formats vowelconsonant-consonant-vowel (e.g., "acme") and vowel-consonant-vowel-consonant (e.g., "anon") are of course two-syllable. Words such as "ache" are possible, but rare. Use of words five or more letters in length will lead to problems in controlling the number of syllables, and to extreme eccentricity with laterally presented stimuli. We can therefore ask whether the findings that field differences occur only for changes within the word, and that these changes are also detected more slowly than ones occurring at initial and final positions, are due to differences in vowel-consonant ratios at these positions. We may note, however, that in auditory studies vowels unlike consonants are not associated with the traditional left-hemisphere superiorities (Darwin, 1971; Shankweiler \& Studdert-Kennedy, 1967). Moreover, inspection of the materials and findings reported here shows that over three times as many vowels occur at the second position as at the third, yet both occupy central bounded positions, both give almost equally strong right-field superiorities, and both give slower detection times when compared with the two unbounded positions. We must therefore conclude that vowel-consonant differences are unlikely to underlie the major effects reported.

It could be argued that there is the further possibility of artefact, since each of the four nontarget words in each word group was repeated twice only, once in each visual field. Each target word, however, was repeated four times in each visual field, so that, overall, the number of target and nontarget words were equal. Consequently, the faster processing of target material could have resulted from some form of sensory facilitation through repetition, even though the nontarget material itself, differing only by a single letter, should have enjoyed an almost equal advantage. However, to check for this, a modified measure of target decision times was obtained by sampling only the values of first occurrence, left and right visual field, for each word group. This meant that the later-occurring six values were ignored. When this was done, it was found that there was a slight decrease in target decision times. The values for first occurrence with overall means in parentheses are as follows: right visual field, $569 \mathrm{msec}$ (580); left visual field, $601 \mathrm{msec}(602)$. The larger field difference is still significant, $\mathrm{t}(15)=3.5, \mathrm{p}<.01$. Consequently, it can be concluded that the faster processing of target words and the field differences are genuine effects.

The total number of replacements (errors and long reaction times as defined earlier) was also calculated for the 16 subjects. Replacements were more frequent with stimuli in the left visual field (310) than with those in the right $(190), F(1,14)=35.5, p<.001$, and with nontarget (281) than with target (219) items, $F(1,14)=6.9, \mathrm{p}<.025$. While females $(218)$ made rather fewer errors than males (282), this difference was not significant, nor were any interactions. Consequently, it can be concluded that the replacement scores generally conformed to the reaction time data.

From the results of this first experiment on word recognition, we can conclude that target items are identified faster than nontargets, which argues against serial-exhaustive letter processing. However, as Nickerson (1972) points out, response times 
for negative responses, especially for nonsimultaneous stimuli as here, are frequently longer. Targets are also associated with a strong right-field superiority. Nontargets likewise do not appear to be processed by any simple left-to-right scan, despite fastest rejection of all where a change occurs in the initial position, since a change at the end position is recognized next fastest, and significantly faster than one at the penultimate position. Moreover, these fast-processed initial and final positions are not associated with any visual field differences, unlike the two middle positions where the expected rightfield superiority is apparent. Otherwise, the general shape of the two laterality functions is closely similar. The only support for any contribution from an unidirectional processing scan comes from the fact that, of the unbounded end positions, Position 4 is processed significantly more slowly than Position 1, and Position 3 in the middle is nonsignificantly slower than Position 2. Further consideration will be given to these points in the general discussion below.

\section{EXPERIMENT 2}

The first experiment employing a word recognition task showed that in two ways the unbounded (initial and final) and the medial letters are processed differently. The second experiment aimed to investigate further the effect of changes at bounded and unbounded positions, together with the extent of parallel letter processing, by determining whether in nontargets detection would be further facilitated by another change to the right of an existing change. We also asked whether nontargets which were completely different, by all four letters, from target items would be immediately apprehended, and perhaps even given a general advantage to the right hemisphere (cf. Egeth \& Epstein, 1972). Indeed, the single-letter changes in Experiment 1 might have tended to induce a serial processing strategy, as suggested by comparisons between changes at 1 and 4 and at 2 and 3. Consequently, it seemed additionally desirable to include nontargets with changes at two and at all four positions. Finally, we wished to determine further the extent and limits of differential hemispheric superiorities and processing strategies in these contexts. As additional controls, larger samples of material were employed, and were constructed so that changes in outline word shape, in terms of patterns of ascenders and descenders, could no longer act as cues for target identity or difference.

\section{Method}

Subjects. A new group of 16 subjects ( $8 \mathrm{male}$ and 8 female) were recruited and screened exactly as in the last experiment.

Materials. In the first experiment, letter shape (and, in consequence, outline word shape) in terms of ascenders and descenders had been uncontrolled. In the second experiment, this was rectified by breaking the alphabet into three subsets: a c e $1 \mathrm{~m} \mathrm{n}$ or s u $v$ w y $\mathrm{z}$ (no ascenders or descenders; dot removed from above i); b d f h k l t (ascenders); g j p q y (descenders; dot removed from above j). Whenever, in a nontarget item, a letter was changed, it was replaced by another member from the appropriate subset. As before, four types of change were generated, though this time the changes were as follows, given a target word such as "c a r t": (1) Position 2, cu r t; (2) Positions 2 and 3, $\mathrm{co}$ a t; (3) Positions 1 and 4, w a $r \mathrm{~d}$; (4) all four positions, s e $\mathrm{n} d$. No letter was ever repeated within a word. Thirty-two families of such words were generated for the experimental series, with two more for practice. No words were ever repeated a second time in another word family. As in Experiment 1 , there were 16 presentations within each family, 8 targets (4 in each field) and 8 nontargets (i.e., one of each type in each visual field). This led to an experimental session of 512 trials.

Procedure. All other aspects of presentation and response were identical to Experiment 1, with the exception that, before each block of trials corresponding to one of the 32 word families, subjects were shown the five words typed on a card, the four nontargets, randomly distributed at each corner, and the target in the middle. The subjects were asked to become familiar with the items, and as before they copied down the target five times. In this way, it was hoped further to equate familiarity across all the items, and also to reduce the error rate, especially now that words could no longer be so readily distinguished by shape in terms of ascenders and descenders.

\section{Results}

The data (see Figure 2) were subjected to analysis of variance as in Experiment 1. Females (604 msec) were again nonsignificantly faster than males $(634 \mathrm{msec})$. Target stimuli $(595 \mathrm{msec})$ were again detected significantly faster than nontargets $(643 \mathrm{msec}), F(1,14)=39.8, p<.001$. The right visual field (609 msec) again was significantly faster than the left $(629 \mathrm{msec}), F(1,14)=27.2, p<.001$. This time, one interaction reached significance, Target by Visual Field, $F(1,14)=13.7, p<.01$, with a greater right-field superiority $(25 \mathrm{msec})$ for target stimuli than for nontargets $(10 \mathrm{msec})$. Comparable values had been apparent in the first experiment ( 24 and $15 \mathrm{msec}$, respectively) but had failed to reach significance.

It is again desirable to examine separately the data for the four types of change position. When this is done, Sex is again nonsignificant, the right visual field ( $636 \mathrm{msec}$ ) continues to be significantly faster than the left $(650 \mathrm{msec}), F(1,14)=14.5, p<.01$, and the main effect Change is also significant, $F(1,14)=116.7, p<.001$. The only significant interaction is, as in Experiment 1 , Change by Visual Field, $F(1,14)=7.69, p<.05$, confirming that the strength of the right-field superiority varies across the different change positions. Using $t$ tests for correlated samples, a significant right-field superiority is once more found only for the middle two positions, 2 and $2+3$, respectively, $t(15)=4.8, p<$ .001 , and $t(15)=4.9, p<.001$. The field differences for the two end positions $(1+4)$ and where all positions are changed $(1+2+3+4)$ are both 


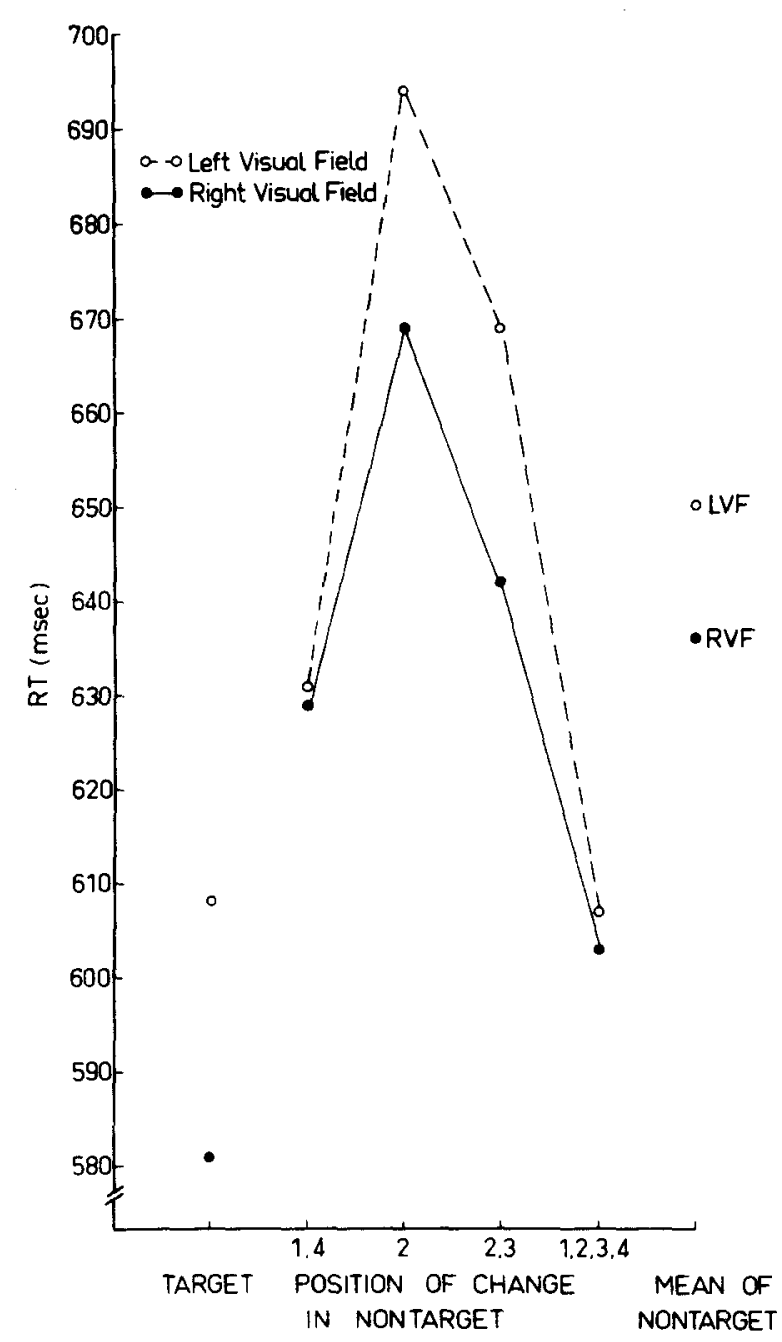

Figure 2. Reaction times averaged across 16 subjects in Experiment 2 for target words and for nontargets differing from targets at first and last letter positions, second letter position, second and third, and at all four positions. Left and right visual fields shown separately.

nonsignificant. These results are exactly comparable to those of the first experiment. Using the NewmanKeuls procedure and collapsing across fields, it is possible to ascertain that times for all change positions are significantly different from each other, all at $p<.01$. In particular, this means that $1+2+$ $3+4$ is significantly faster than both $1+4$ and $2+3$ alone, and that $2+3$ is significantly faster than 2 alone and slower than $1+4$. Once again, we must conclude not only that field differences are only found for changes in the middle positions of the word, but also that changes at the beginnings and ends, and throughout the whole word, are detected faster than and differently from changes in the middle. Again, the fact that $2+3$ is faster than 2 and that $1+2+3+4$ is faster than $1+4$ argues against a serial left-to-right scan and is consistent with some form of parallel-interactive processing. The superiority of $1+4$ relative to $2+3$ emphasizes the fact that processing apparently commences at the initial and final positions.

Just as in Experiment 1, a modified measure of target decision times was obtained by sampling only the values of first occurrence of target, in each field, for each word group. It was found that, as before, the field difference increased somewhat with firstoccurrence values, as compared with those for the overall mean. The values for first occurrence, with overall means in parentheses, are as follows: right visual field, $586 \mathrm{msec}$ (581); left visual field, $620 \mathrm{msec}$ (608). The (larger) field difference is still significant, $\mathrm{t}(15)=4.5, \mathrm{p}<.001$.

The total number of replacements was calculated for the 16 subjects ( 512 trials per subject). Replacements were again rather more frequent with stimuli in the left field (173) than in the right (126), though this time the difference was nonsignificant. Nontargets (178) were again replaced significantly more often than targets $(121), F(1,14)=5.71, p<.05$. This time the females' superiority (102) over males (197) reached significance, $F(1,14)=6.46, p<.025)$. There were no interactions approaching significance. Consequently, it can again be concluded that the replacement scores generally conformed to the reaction time data. Despite the greater number of trials, and perhaps as a result of letting subjects examine the target and nontarget items before each block, there was a considerable overall decrease in replacement rate in this second experiment (299) as compared with the first (500).

\section{DISCUSSION}

In both experiments, target stimuli gave strong right-field superiorities, and were recognized faster than nontargets. A strict left-to-right scan would predict fastest overall reaction times for nontargets with a change at the first position, and slowest for targets (since all letters have first to be checked); the next slowest would be nontargets with a change at the last position. Obviously, the data are incompatible with such a strict model. However, one should be cautious about directly comparing times for target and nontarget judgments; for the latter, the evidence is contradictory (except where all letters differ, there will also be some letters matching), whereas for targets, there is no such conflict. Moreover, decision times for negative responses are usually longer, especially where stimuli are not simultaneous (Nickerson, 1972), though this effect may occur at the decision rather than at the comparison phase (Sternberg, 1975). When in Experiment 2 we compare target and nontarget judgments (in the latter case where all four letters changed, and there 
is no conflict), the two sets of values summed across fields are almost identical. However, in the case of the target judgments, the right field is strongly superior to the left, whereas with the nontarget judgments the fields scarcely differ. We must conclude therefore that two different processing mechanisms probably serve the two types of response, and that there are different underlying laterality effects associated with them. A similar conclusion was reached by Bradshaw, Gates, and Patterson (1976) in the context of nonverbal, geometric, and pattern processing.

Are target judgments being made on the basis of a rapid, physical, whole-word match? Work with simultaneously presented letter pairs has shown that physical matches (e.g., AA, bb) are detected faster overall, and are more readily performed in the right hemisphere (Cohen, 1972; Davis \& Schmit, 1973; Geffen et al., 1972; Umiltà et al., 1972). However, in the two present experiments, words rather than discrete letters were being matched, and at a memory rather than a purely perceptual (i.e., simultaneous presentation) level. Henderson and Henderson (1975) presented uppercase (unlike our lowercase) words and letter strings across fixation, with nontarget items differing from targets at various letter positions. They, too, found that targets were identified faster than nontargets. They concluded that some sort of holistic matching process was responsible, which was less sensitive to the number of critical features in the display (cf. Bamber, 1969; Beller, 1970; Egeth \& Blecker, 1971). Henderson and Henderson found evidence that such a holistic process was even more apparent for word, as compared with letter-string, stimuli. If this is true, we must conclude, on the basis of the strong left-hemisphere superiority with our target stimuli, that the left hemisphere is nore capable than the right at performing rapid rolistic matches. This runs contrary to recent con:lusions (Bogen, 1975; Cohen, 1973; Levy, 1974; Nebes, 1972; Patterson \& Bradshaw, 1975) that the ight hemisphere's specialization is for holistic gestalt Ippreciation of similarity or identity. However, the act that in Experiment 2 word shape was kept fairly :onstant (by equating target and nontarget items at tll times for ascenders and descenders), and the fact hat responses to targets (first occurrence, or mean if all occurrences) were approximately equal to esponses when all four letters differed, argues somevhat against a holistic apprehension of word shape. $t$ is, however, compatible with a rapid mode of arallel processing (cf. Estes, in press) where a target an be readily identified in the absence of any contraictory information.

In their task described above, Henderson and Ienderson (1975) were also concerned with the issue f serial left-to-right processing. However, they used he relatively less familiar uppercase stimuli, where the absence of ascenders and descenders destroys information as to word shape, and they interspersed real words with letter strings. Consequently, subjects could have tended to adopt a nonword serial type of processing throughout-a criticism which can also be made of the similar study of Chambers and Forster (1975), where simultaneous rather than memory matching was employed. While, as a result perhaps of these factors, Chambers and Forster did find evidence of serial position effects with their word stimuli, compatible with a left-to-right processing scan, Henderson and Henderson only obtained such an effect with their nonword strings. The function for their word stimuli was identical to ours-an ascending serial position effect with a downward deflection for the last letter. Moreover, exactly as we found, response times where only the first position differed were considerably slower than where other positions to the right also differed, which is indicative of some kind of parallel processing. Further evidence against the operation of a serial left-to-right scan comes from work with letter strings themselves. Stimuli such as these we deliberately rejected for the present studies, lest their nature, and the more difficult task, artificially induced a serial scan. Merikle and Glick (1976) review the W-shaped function typically found with accuracy for partial report of superspan strings presented across fixation. Estes, Allmeyer, and Reder (1976) give similar consideration to subspan full report of unilaterally presented letter strings. In both cases, performance for the very first item on the extreme left is superior to that of the first item immediately to the right of the fixation point; performance for the very last item on the extreme right is superior to that of the last item immediately to the left of the fixation point; performance for internal items on the right side of fixation is better than for the corresponding internal items to the left of fixation. Overall, the internal items are processed less well than those at the beginning and end of the string. These findings with nonword letter strings are exactly similar to our data in Experiment 1 (nontargets, see Figure 1). Estes (in press) concludes that effects such as these are due to a combination of several factors, including a central-peripheral acuity gradient, lateral masking effects between neighboring letters, and a contribution from cerebral asymmetry. The beginnings-ends superiority supports an observation originally made by Bruner and O'Dowd (1958) using words, and is confirmed by, among others, Rayner and Hagelberg (1975). The latter workers used letter strings and showed that the leftmost letter position in an item is the most important, and the rightmost the next, despite the fact that these letters may be furthest from the fovea. Similar findings are discussed by Eriksen and Eriksen (1974), who measured vocal initiation times when 
presentation of various letter positions within a word was delayed relative to the other letters.

As Estes (in press) observes, word perception is a varying admixture of sensory, memory, decision, and response encoding factors, rather than a single unitary mechanism. Nevertheless, the data permit the following conclusions to be drawn, conclusions which are necessarily restricted to the paradigm and material employed. The presence of effects from the position and number of changed letters in the nontargets argues against a comparison on a semantic and, probably, an acoustic level. Serial left-to-right processing, if it operates at all, seems fairly unimportant, though the data are not inconsistent with serial comparisons having random entry, or even where there is a bias favoring the beginnings and ends of a word (where neither hemisphere is superior) over the middle of a word. It is with respect to the latter that a strong left-hemisphere contribution is manifest. These results, for reasons discussed earlier, probably do not stem from differences in the vowel-toconsonant ratio at different letter positions. Parallel interactive processing is certainly involved, as the more the letters there are that differ from the target, the readier the response, and the presence of an additional change to the right of an existing one leads to faster performance. The fact that, in Experiment 2, word shape was kept fairly constant (by equating target and nontarget items for ascenders and descenders), and the fact that responses to targets were approximately equal to responses when all four letters differed, argues somewhat against a holistic apprehension of word shape, as well as against a serial processing mechanism. It is, however, compatible with a rapid mode of parallel processing where a target can be readily identified in the absence of any contradictory information. Thus, in both cases, all four letters are either the same as or different from those of the target. The unresolved question, however, is why this rapid parallel processing, which leads, respectively, either to a target or nontarget judgment in the above circumstances, should be associated with a strong right-field superiority in the case of target stimuli and the absence of any field differences whatsoever in the case of nontargets where all four letters differed. Future experimentation should be addressed to this issue.

\section{REFERENCES}

BAMBER, D. Reaction times and error rates for same-different judgments of multi-dimensional stimuli. Perception \& Psychophysics, 1969, 6, 169-174.

Barton, M. I., Goodglass, H., \& Shai, A. Differential recognition of tachistoscopially presented English and Hebrew words in right and left visual fields. Perceptual and Motor Skills, 1965, 21, 431-437.

Beller, H. K. Parallel and serial stages in matching. Journal of Experimental Psychology, 1970, 84, 213-219.
Bogen, J. E. Some educational aspects of hemispheric specialization. USLA Educator, 1975, 17, 24-32.

BRADSAAw, J. L. Three interrelated problems in reading. Memory \& Cognition, 1975, 3, 123-134.

Bradshaw, J. L., Bradley, D., \& Patterson, K. The perception and identification of mirror reversed patterns. Quarterly Journal of Experimental Psychology, 1976, 28, 221-246.

Bradshaw, J. L., Gates, A., \& Patterson, K. Hemispheric differences in processing visual patterns. Quarterly Journal of Experimental Psychology, 1976, 28, 667-681.

Bruner, J. S., \& O'DOWD, D. A note on the informativeness of parts of words. Language and Speech, 1958, 1, 98-101.

BRYDEN, M. P., \& Alcaro, F. Visual hemifield differences depend upon typeface. Brain and Language, 1976, 3, 191-200.

Caplan, D., Holmes, J. M., \& Marshall, J. C. Word classes and hemispheric specialization. Neuropsychologia, 1974, 12, 331-337.

Carmon, A., Kleiner, M., \& Nachshon, I. Visual hemifield effects in dichoptic presentation of digits. Neuropsychologia, $1975,13,289-295$.

Carmon, A., Nachshon, I., Isseroff, A., \& KLeiner, M. Visual field differences in reaction time to Hebrew letters. Psychonomic Science, 1972, 28, 222-224.

Chambers, S. M., \& Forster, K. I. Evidence for lexical access in a simultaneous matching task. Memory \& Cognition, 1975, 3, 549-559.

COHEN, G. Hemispheric differences in a letter classification task. Perception \& Psychophysics, 1972, 11, 139-142.

Cones, G. Hemisphere differences in serial versus parallel processing. Journal of Experimental Psychology, 1973, 97, 349-356.

CoHen, G. Hemispheric differences in the utilization of advance information. In P. Rabbitt \& S. Dornic (Eds.), Attention and performance V. New York: Academic Press, 1974. Pp. 20-32.

CoHeN, G. Components of the laterality effect in letter recognition: Asymmetries in iconic storage. Quarterly Journal of Experimental Psychology, 1976, 28, 105-114.

DARWIN, C. J. Ear differences in the recall of fricatives and vowels. Quarterly Joumal of Experimental Psychology, 1971, 23, 46-62.

DAvis, R., \& Schmir, V. Visual and verbal coding in the interhemispheric transfer of information. Acta Psychologica, 1973, 37, 229-240.

Egeth, H., \& Blecker, D. Differential effects of familiarity on judgments of sameness and difference. Perception \& Psychophysics, 1971, 9, 321-326.

EgETH, H., \& EPSTEIN, J. Differential specialization of the cerebral hemispheres for the perception of sameness and difference. Perception \& Psychophysics, 1972, 12, 218-220.

Ellis, H. D., \& SHePherd, J. W. Recognition of abstract and concrete words presented in left and right visual fields. Journal of Experimental Psychology, 1974, 103, 1035-1036.

ERIKSEN, B. A., \& ERIKSEN, C. W. The importance of being first: A tachistoscopic study of the contribution of each letter to the recognition of four-letter words. Perception \& Psychophysics, 1974, 15, 66-72.

Estes, W. K. Perceptual processing in letter recognition and reading. In E. C. Carterette \& M. P. Friedman (Eds.), Handbook of perception (Vol. IX). New York: Academic Press, in press.

Estes, W. K., Allmeyer, D. H., \& Reder, S. M. Serial position functions for letter identification at brief and extended exposure durations. Perception \& Psychophysics, 1976, 19, 1-15.

Geffen, G., Bradskaw, J. L., \& Nettleton, N. C. Hemispheric asymmetry: Verbal and spatial encoding of visual stimuli. Journal of Experimental Psychology, 1972, 95, 25-31.

Gefpen, G., Bradshaw, J. L., \& Nettleton, N. C. Attention and hemispheric differences in reaction time during simultaneous audiovisual tasks. Quarterly Joumal of Experimental Psychology, 1973, 25, 404-412.

Geffew, G., Bradsanw, J. L., \& Wallace, G. Interhemispheric effects on reaction time to verbal and nonverbal visual stimuli. Journal of Experimental Psychology, 1971, 87, 415-422. 
Henderson, L., \& Henderson, S. E. Visual comparison of words and random letter strings: Effects of number and position of letters different. Memory \& Cognition, 1975, 3, 97-101.

Hines, D. Recognition of verbs, abstract nouns and concrete nouns from left and right visual half fields. Neuropsychologia, 1976, 14, 211-216.

Hines, D., \& SATZ, P. Superiority of right visual half-fields in right handers for recall of digits presented at varying rates. Neuropsychologia, 1971, 9, 21-25.

Isseroff, A., CArmon, A., \& NAChshon, I. Dissociation of hemifield reaction times from verbal stimulus directionality. Journal of Experimental Psychology, 1974, 103, 145-149.

JoYNT, R. J., \& GolnsteIN, M. N. Minor cerebral hemisphere. In W. J. Friedlander (Ed.), Advances in neurology (Vol. 7) Current reviews of higher nervous system dysfunction. New York: Raven Press, 1975. Pp. 147-183.

KuČera, H., \& Francis, W. N. Computational analysis of present day English. Providence, R.I: Brown University Press, 1967.

LEVY, J. Psychological implications of bilateral asymmetry. In S. J. Dimond J. G. Beaumont (Eds.), Hemisphere function and the human brain. London: Elek, 1974. Pp. 121-183.

MCKeEVer, W. F., Gill, K. M., \& VAN Deventer, A. D. Letter versus dot stimuli as tools for splitting the normal brain with reaction time. Quarterly Journal of Experimental Psychology, $1975,27,363-373$.

MARCEL, T., KATZ, L., \& SMTrH, M. Laterality and reading proficiency. Neuropsychologia, 1974, 12, 131-139.

Marcel, T., \& Patterson, K. Word recognition and production: Reciprocity in clinical and normal studies. To appear in $\mathrm{J}$. Requin (Ed.), Attention and performance VII. New Jersey: Lawrence Erlbaum, in press.

Merukle, P. M., \& Glick, M. J. Processing order in visual perception. Quarterly Journal of Experimental Psychology, 1976, 28, 17.26

Moscovitch, M. Language and the cerebral hemispheres: Reaction time studies and their implications for models of cerebral dominance. In P. Pliner, T. Alloway, \& L. Krames (Eds.), Communication and affect: Language and thought. New York: Academic Press, 1973. Pp. 89-126.

NebEs, R. D. Dominance of the minor hemisphere in com- commissurotomized man on a test of figural unification. Brain, $1972,95,633-638$.

Nickerson, R. S. Binary classificatory reaction time: A review of some studies of human information-processing capabilities. Psychonomic Monograph Supplements, 1972, 417. Whole No. 65).

Patterson, K., \& Bradshaw, J. L. Differential hemispheric mediation of non-verbal visual stimuli. Journal of Experimental Psychology: Human Perception and Performance, 1975, 1, 246-252.

RAYNer, K., \& HAgelberg, E. M. Word recognition cues for beginning and skilled readers. Journal of Experimental Child Psychology, 1975, 20, 444-455.

Rizzolatti, G., Umilta, C., \& Berluccer, G. Opposite superiorities of the right and left cerebral hemis pheres in discriminative reaction time to physiognomical and asphabetical material. Brain, 1971, 94, 431-442.

ShankWeiler, D., \& Studdert-Kennedy, M. Identification of consonants and vowels presented to left and right ears. Quarterly Journal of Experimental Psychology, 1967, 19, 59-63.

Sternberg, $S$. Memory scanning: New findings and current controversies. In D. Deutsch \& J. A. Deutsch (Eds.), Short term memory. New York: Academic Press, 1975.

Umilta, C., Frost, N., \& Hyman, R. Interhemispheric effects on choice reaction time to one-, two-, and three-letter displays. Journal of Experimental Psychology, 1972, 93, 198-204.

Vincent, T., Bradshaw, J. L., Nettleton, N. C., \& Donahoo, K. A projection tachistoscope employing two automatic projectors with phototransistor control of sequencing. Behavior Research Methods \& Instrumentation, 1973, 5, 477-480.

WвIтE, M. J. Laterality differences in perception: A review. Psychological Bulletin, 1969, 72, 387.405.

White, M. J. Does cerebral dominance offer a sufficient explanation for laterality differences in tachistoscopic recognition? Perceptual and Motor Skills, 1973, 36, 479-485.

WINER, B. J. Statistical principles in experimental design (2nd ed.). New York: McGraw-Hill, 1971.

(Received for publication August 9, 1976; revision received March 4, 1977.) 